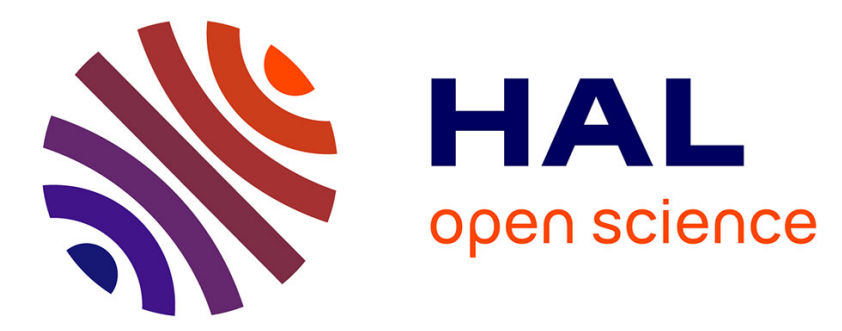

\title{
Structural modifications and thermal transitions of standard maize starch after DIC hydrothermal treatment
}

Zoulikha Maache-Rezzoug, Ikbal Zarguili, Catherine Loisel, D. Queveau, Alain Buleon

\section{To cite this version:}

Zoulikha Maache-Rezzoug, Ikbal Zarguili, Catherine Loisel, D. Queveau, Alain Buleon. Structural modifications and thermal transitions of standard maize starch after DIC hydrothermal treatment. Carbohydrate Polymers, 2008, 74 (4), pp.802-812. 10.1016/j.carbpol.2008.04.047 . hal-00413469

\author{
HAL Id: hal-00413469 \\ https://hal.science/hal-00413469
}

Submitted on 4 Sep 2009

HAL is a multi-disciplinary open access archive for the deposit and dissemination of scientific research documents, whether they are published or not. The documents may come from teaching and research institutions in France or abroad, or from public or private research centers.
L'archive ouverte pluridisciplinaire HAL, est destinée au dépôt et à la diffusion de documents scientifiques de niveau recherche, publiés ou non, émanant des établissements d'enseignement et de recherche français ou étrangers, des laboratoires publics ou privés. 


\section{STRUCTURAL MODIFICATIONS AND THERMAL TRANSITIONS OF STANDARD}

MAIZE STARCH AFTER D.I.C HYDROTHERMAL TREATMENT

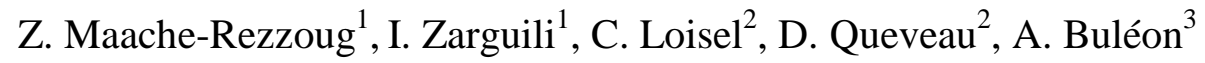

(1) Université de la Rochelle, Laboratoire LEPTIAB, av. M. Crepeau, 17042 La Rochelle, France

(2) Laboratoire GEPEA, ENITIAA rue de la Géraudière, BP 82225, 44322 Nantes Cedex 3, France

(3) UPCM-INRA, BP 71627, 44316 Nantes Cedex 3, France

Author to whom correspondence should be addressed

Z. Maache-Rezzoug

Université de La Rochelle - Pôle Sciences

Laboratoire d'Etude des Phénomènes de Transfert et de l'Instantanéité : Agro-Industrie et Bâtiment.

Avenue Michel Crépeau 17042 La Rochelle - France

Tél : (33) $0546458615 \quad$ Fax : (33) $0546458616 \quad$ e-mail : $\quad \underline{\text { zrezzoug@univ-Ir.fr }}$ 
Abstract

Standard maize starch was hydrothermally treated by Instantaneous Controlled Pressure Drop (DIC) process at three pressure levels (1,2 and 3 bar) corresponding to the temperatures of 100,122 and $135{ }^{\circ} \mathrm{C}$ (at $13-27 \%$ moisture), respectively. The structural effects of various hydrothermal conditions were examined with differential scanning calorimetry (DSC) and wide-angle X-ray diffraction. In order to understand the changes that occur during DIC treatment, melting endotherms of native maize starch at various moisture contents were determined. The gelatinization temperatures of DIC treated standard maize starch increased with DIC treatment. The transition temperatures $\left(\mathrm{T}_{\mathrm{o}}, \mathrm{T}_{\mathrm{p}}\right)$ are closely related to the combined effect of pressure and processing time. At approximately 10 min of processing time, $T_{o}$ and $T_{p}$ were 65.7 and $72.3{ }^{\circ} \mathrm{C}, 68.8$ and $73.6{ }^{\circ} \mathrm{C}, 74.8$ and $79.8{ }^{\circ} \mathrm{C}$ for pressure levels of 1,2 and 3 bar, respectively (against 63.1 and $69.6^{\circ} \mathrm{C}$ for native starch). DIC treatment narrowed the gelatinization temperature range and decreased gelatinization enthalpy $(\Delta \mathrm{H})$, as the severity of processing conditions increased. $\Delta \mathrm{H}$ decreased from $11.4{\mathrm{~J} . \mathrm{g}^{-1}}^{-1}$ native) to 11.0 (1 bar), 9.0 (2 bar) and $1.7 \mathrm{~J} . \mathrm{g}^{-1}$ (3 bar) for treated maize starch during approximately $10 \mathrm{~min}$. Relative crystallinity of hydrothermally treated starch decreased with increasing DIC conditions. The A-type crystalline pattern was progressively lost (at pressure level $\geq 2$ bar) and substituted by the $\mathrm{V}_{\mathrm{h}}$-type $\mathrm{X}$-ray diffraction pattern, corresponding to the formation of amylose-lipid complexes. For severe DIC conditions (pressure level of 3 bar), the substitution was completed. Microscopic observations revealed progressive loss of the birefringence of DIC treated starch granules except at low pressure (1 bar), while the integrity of starch granules was preserved for all the conditions. These modifications that reveal important changes in the crystalline organization of the starch granules are related to their functional properties. 


\section{Introduction}

Starch is one of the most important natural polymers and its use depends largely on its functional properties. The comprehension of starch phase transitions is extremely important in the food processing operations and the physical properties of food products. Due to the semicrystalline structure of starch, two phase transitions are likely to occur during the thermal treatment of starch-water systems: the glass transition that concerns the amorphous phase (mainly the branching regions of the amylopectin and most of the amylose chains) and the melting of crystallites (formed by adjacent short chains of amylopectin intertwined into double helices). The melting of crystallites can be detected by X-ray diffraction patterns, and differential scanning calorimetry (Donovan, 1979, Biliaderis, Maurice \& Vose, 1980; Hoseney, Zeleznak \& Lai, 1986; Garcia, Colonna, Lourdin, Buléon, Bizot \& Ollivon, 1996; Cruz-Orea, Pitsi, Jamee \& Thoen, 2002; Ratnayake \& Jackson, 2007). The melting temperatures $\left(\mathrm{T}_{\mathrm{m}}\right)$ of starch-water system strongly depend on the water content. For water content greater than $60 \%(\mathrm{w} / \mathrm{w})$, the temperature is referred to as starch gelatinization temperature and a single endotherm is observed on the DSC profile. The irreversible changes taking place during gelatinization, namely diffusion of water into the starch granules and swelling of the granules are accompanied by an increase of the viscosity which is responsible for the thickening effect of starch in food products. For lower water contents, multiple transitions occur that reflect melting and recrystallisation processes occurring simultaneously during heating (Biliaderis, Page, Maurice \& Juliano, 1986): the transition temperatures referred to as melting temperatures increase and multiple endotherms are formed to the detriment of the former gelatinization endotherm. Concerning the cereal starches, another endotherm appears over the temperature range of $90-120^{\circ} \mathrm{C}$, due to the melting of amyloselipid complexes (Biliaderis, 1991) that may form during gelatinization. These structures give a V-type X-ray diffraction pattern. 
The textural properties of starch dispersions are for a major part due to the swelling capacity of starch granules. In the food and non-food industries, starch systems are submitted to intensive heat and shear treatments during sterilisation or homogenisation-mixing respectively; these treatments alter the integrity of starch granules and impair the functional properties of the suspensions. Modified starches have been therefore developed to improve the resistance of starch dispersions to industrial treatments. Nowadays, there is considerable interest in physical modifications, which are considered to be safer than chemical ones especially for food applications with novel functional properties. Physical modifications can be obtained through the controlled application of heat and moisture treatment. Annealing and heat moisture treatments (HMT) (Jacobs, Mischenko, Koch, Eerlingen, Delcour. \& Reynaers, 1998; Tester, Debon \& Sommerville, 2000; Vermeylen, Goderis \& Delcour, 2006; Tukomane, Leerapongnum, Shobsngob \& Varavinit, 2007; Kulp \& Lorenz, 1981; Hoover \& Manuel, 1996; Collado \& Corke, 1999; Gunaratne \& Hoover, 2002; Gunaratne \& Corke, 2007) are the two most usual physical treatments by which the semi-crystalline structure of starch granules are modified without disrupting the granule (Lim, Chang, \& Chung, 2001). The differences between these two treatments are the water content and the temperature used. The annealing occurs under large excess of water (50 to 60\%) and relatively low temperatures (below the gelatinization temperature), while the HMT is conducted under restricted moisture content $(10-30 \%)$ and higher temperatures $\left(90-120^{\circ} \mathrm{C}\right)$. Both treatments are applied over large periods of time (10-16h).

Many studies have been carried out on the structural and physical properties of starches after HMT treatment since the first experimentations conducted by Sair \& Fetzer in 1944. The properties of heat moisture treated starches depend on the starch origin (Gunaratne et al., 2002; Hoover \& Vasanthan, 1994; Hoover et al., 1996; Kulp et al., 1981; Collado et al., 1999) and treatment conditions used (Takaya \& Nishinari, 2000; Collado et al., 1999). Generally the 
HMT is known to reduce the water sorption capacity, the swelling capacity of starch granules as well as the viscosity of the starch suspension. The initial temperature of gelatinization $\left(\mathrm{T}_{0}\right)$ and the temperature of the peak $\left(T_{p}\right)$ increase; in the meanwhile, the gelatinization enthalpy decreases and the endotherm of gelatinization is broadened (Sair 1967; Kulp et al., 1981; Stute, 1992; Hoover et al., 1994; Gunaratne et al., 2002; Vermeylen et al., 2006). The intensity of the modifications depends on the water content and the temperature/time conditions of the treatment. Buléon \& Bertrand (1982) reported an increased susceptibility to hydrolysis that they ascribed to partial gelatinization of starch granules after HMT treatment.

HMT starches have generally been produced on a laboratory scale and many authors have reported that such conditions produce inhomogeneous samples with partially hydrotreated starch granules. For HMT, vapour pressure is often required to assure sufficient heating, but uniform heat distribution and penetration into the starch is not easy to accomplish. Maruta, et al. (1994) improved the conventional method of the HMT by creating a reduced pressure in the vessel containing the starch before the injection of live steam. This method was designated by Maruta et al. (1994) as the reduced-pressurized heat moisture treatment (RPHMT). The DIC hydrothermal process, developed at a laboratory as well as pilot scale (Rezzoug, Maache-Rezzoug, Mazoyer \& Allaf, 2000) some years ago is closer to RP-HMT treatment proposed by Maruta et al. (1994). The difference is that the DIC treatment is followed by an abrupt pressure drop towards vacuum pressure. This step induces a rapid modification of the thermodynamic equilibrium reached during the pressurisation $\left(\mathrm{P}_{1}, \mathrm{~T}_{1}\right)$ towards another equilibrium state $\left(\mathrm{P}_{2}, \mathrm{~T}_{2}\right)$. This new state induces a rapid cooling and the resulting temperature value depends on the vacuum pressure level. The DIC treatment (Instantaneous Controlled Pressure Drop) is a recent process patented and developed in our laboratory (Allaf, Louka, Bouvier, Parent \& Forget, 1993) for drying and texturizing food products such as pasta products (Maache-Rezzoug \& Allaf, 2005). As for the RP-HMT 
process, the instauration of an initial vacuum of 50 mbar before injection of steam at high pressure allows to reduce the resistance of air, thus facilitating the diffusion of steam into the product (Zarguili, Maache-Rezzoug, Loisel \& Doublier, 2006). Consequently, the time necessary to reach the steam temperature equilibrium is reduced with homogeneous vapour diffusion and a more effective heat transfer to the starch. In a recent laboratory study, the thickness of the layer of maize starch which can be treated in the DIC equipment to assess uniform heat distribution and homogeneous diffusion of steam into the starch powder has been fixed to $0.5 \mathrm{~cm}$ (Zarguili et al., 2006); the time required to reach the equilibrium temperature was $80,60,45$ and $20 \mathrm{~s}$ for processing pressures of 2, 3, 4 and 5 bar, respectively.

The DIC hydrothermal treatment was applied to starches aiming to produce structural modifications and thus modifying their functional properties. A preliminary study on the application of DIC hydrothermal treatment on standard and waxy maize starches (Loisel, Maache-Rezzoug, Esneault \& Doublier (2006) showed a partial gelatinization of the treated samples. The occurrence of partial gelatinization was clearly attested by the decrease of the gelatinization enthalpy and the loss of birefringence under polarized light as the pressures and time of the process increased; the greatest effect being obtained for 2.7 to 3 bar during 200 to 300 seconds. The starch granules were not disrupted after the DIC treatment at initial moisture content of starch, but the viscosity of the starch dispersions pasted in the Viscograph Brabender considerably decreased.

The purpose of this study was to investigate the structural and thermal phase transitions induced in a standard maize starch as a result of DIC hydrothermal treatment. The influence of DIC treatment conditions on the thermal transition and structural characteristics in standard maize starch was investigated using DSC, X-Ray diffraction and polarised light microscopy associated with determination of granule size distribution by laser diffraction. 
2. Materials and methods

\subsection{Materials}

Standard maize starch was supplied by Roquette Frères (Lestrem, France). The moisture content was $12.5 \%$ wet basis.

\subsection{Methods}

\subsubsection{Moisture content}

The starch moisture content was determined by air oven at $105^{\circ} \mathrm{C}$ during $24 \mathrm{~h}$, according to the A.F.N.OR (NF V03-707, 2000) standard method and related to the wet basis (\%, wb).

\subsubsection{DIC hydrothermal treatment}

The equipment and procedure of DIC hydrothermal treatment were largely described in previous studies (Rezzoug et al., 2000; Loisel et al., 2006; Zarguili et al., 2006). During the treatment, starch (12\% wet basis) is placed in the processing vessel. A vacuum of 50 mbar is established. This initial vacuum facilitates the diffusion of steam into product and allows its rapid heating (Zarguili et al., 2006). Saturated steam is then introduced into the vessel at a fixed pressure level ( 1 to 3 bars) and maintained during a determined processing time. In this study the processing pressure was fixed at 1 bar $\left(100{ }^{\circ} \mathrm{C}\right), 2$ bar $\left(122^{\circ} \mathrm{C}\right)$ and 3 bar $\left(135^{\circ} \mathrm{C}\right)$. The pressurisation is followed by an abrupt decompression towards vacuum (50 mbar). After the vacuum phase, atmospheric air is injected to return to atmospheric pressure for sample recovery. During the treatment, starch is heated by the absorption of latent heat of vapour condensation that causes an increase in the moisture content. Zarguili, Maache-Rezzoug, Loisel \& Doublier (2008) modelled this variation of moisture content through a simple model based on gravimetric data. 


\subsubsection{Differential scanning calorimetry (DSC)}

\subsubsection{Phase transition of standard maize starch at different moisture contents}

The phase transitions of the water- maize starch systems were established by using; PYRIS 6 DSC (Perkin-Elmer) for transitions (melting) measured between 100 and $200{ }^{\circ} \mathrm{C}$ (heating rate $2{ }^{\circ} \mathrm{C} / \mathrm{min}$ ), and Micro DSC III (Setaram, France) for transitions (gelatinization) measured between 20 and $100{ }^{\circ} \mathrm{C}$ (heating rate $1.2{ }^{\circ} \mathrm{C} / \mathrm{min}$ ). Water was added to starch in DSC pans which were allowed to stand for $2 \mathrm{~h}$ at room temperature for moisture equilibration. A range of 11.5 to $90 \%$ moisture content was investigated.

\subsubsection{Thermal characteristics of DIC treated maize starch}

Gelatinization parameters were measured using the Micro DSC III (Setaram, France). Starch samples $(800 \mathrm{mg})$ were placed in a stainless pan; distilled water was added to get a ratio of 1:9 (w/w) starch:water, and then the pan was sealed. The reference pan was filled with water. Pans were heated at a rate of $1.2{ }^{\circ} \mathrm{C} / \mathrm{min}$ from 30 to $110^{\circ} \mathrm{C}$. Thermal transitions were defined as $T_{\mathrm{o}}$ (onset temperature), $\mathrm{T}_{\mathrm{P}}$ (peak temperature) and $\Delta \mathrm{H}$ was referred to as the gelatinization enthalpy. The gelatinization temperature range $(R)$ was calculated as $2\left(T_{p}-T_{o}\right)$ as described by Krueger, Knutson, Inglett \& Walke (1987). The residual enthalpy ratio of the treated starch was also calculated by the following equation $R E(\%)=\frac{\Delta H_{t}}{\Delta H_{\text {raw }}} \times 100$, where $\mathrm{RE}$ is the residual enthalpy ratio, $\Delta \mathrm{H}_{\mathrm{t}}$ the gelatinization enthalpy of the residual structure after DIC treated starch and $\Delta \mathrm{H}_{\text {raw }}$ the gelatinization enthalpy of the native starch.

Determination of the amylose-lipid complex

We used DSC Q10 (TA-Instrument, France) for measuring the thermal transition corresponding to the melting of the amylose-lipid complex: $10 \mathrm{mg}$ of starch suspension $(1: 9$ 
w/w starch:water) were sealed in a stainless pan, and heated from 30 to $130{ }^{\circ} \mathrm{C}$ at a heating rate of $2{ }^{\circ} \mathrm{C} / \mathrm{min}$.

\subsubsection{X-ray diffraction}

Native and DIC-hydrothermal treated maize starches were equilibrated above a saturated barium chloride solution $\left(\mathrm{a}_{\mathrm{w}}=0.95\right)$, and the X-ray diffraction pattern was measured with Inel (France) X-ray equipment at $40 \mathrm{kV}$ and $30 \mathrm{~mA}$. The diagrams of diffraction were recorded according to the method of Debye-Sherrer in transmission for powders. $\mathrm{Cu} \mathrm{K}$-radiation $(\lambda=1.54 \mathrm{~nm})$ was selected using a quartz monochromator. A curved position-sensitive detector CPS 120 was used to monitor diffracted intensities in the $0-120^{\circ}, 2 \theta$ range. Diffraction diagrams were all normalised at the same total scattering value, with $2 \theta$ ranging from 3 to $30^{\circ}$. The crystallinity ratio was calculated according to the method of Wakelin (Wakelin, Virgin \& Crystal, 1959) using spherolitic crystals and dry extruded potato starch as crystalline and amorphous standards respectively.

\subsubsection{Polarised light microscopy}

Dilute native and DIC-hydrothermal standard maize starch suspensions (1:20) were viewed under polarised light (magnifying $400 \mathrm{X}$ ) using a Leica microscope equipped with a CCD camera.

\subsubsection{Granule size distribution}

Granule size determination was carried out at room temperature using a Malvern Master Sizer (Malvern Instruments, Ltd) laser scattering analyser with a $300 \mathrm{~mm}$ Fourier cell (range 0.05$879 \mu \mathrm{m})$. The starch dispersion (6\%) was first diluted (1/10) with demineralized water at $20^{\circ} \mathrm{C}$ before and immediately after the pasting procedure in the Brabender Viscograph then dispersed in the sample dispersion unit $(1 \mathrm{ml} / 100 \mathrm{ml}$ water). The volume distribution was obtained according to the Mie scattering theory (Loisel et al., 2006). From each distribution, 
the median volume diameter $\mathrm{D}(\mathrm{v}, 0.5)$ and the swelling ratio $\left(\mathrm{D} / \mathrm{D}_{0}\right)^{3}$ were presented; the size dispersion was evaluated using the dispersion index referred to as the span, by the following equation: Span : $\frac{D(v, 0.9)-D(v, 0.1)}{D(v, 0.5)}$

\section{Results and discussion}

\subsection{Phase transitions of starch-water system}

In order to understand the changes that occur during DIC hydrothermal treatment, thermal transitions of native standard maize starch for various water contents were determined by differential scanning calorimetry (Fig. 1). The DSC characteristics are presented on Table 1. In a large excess of water (above 70\%) a single endothermic transition is observed for the gelatinization of starch (referred to as $\mathrm{G}$ ). The peak temperatures and gelatinization enthalpy remain constant: $69.8{ }^{\circ} \mathrm{C}$ and $11.5 \mathrm{~J}^{-1}{ }^{-1}$, respectively. For intermediate moisture contents, from 70 to $40 \%$, the enthalpy of the first endotherm decreases, from 9.8 to $1.9 \mathrm{~J} / \mathrm{g}$ (Table 1), although the peak temperature remains constant at about $70{ }^{\circ} \mathrm{C}$. From moisture contents of $35 \%$, a second peak (referred to as $\mathrm{M}$ ) appears while the first peak of gelatinization is further reduced and completely disappears at a moisture content of $26 \%$. The peak temperature and enthalpy of the second peak (M) increase as the moisture content is reduced: from 140 to 184 ${ }^{\circ} \mathrm{C}$ for moisture contents of 26 to $11.5 \%$, respectively. The presence of multiple melting endotherms at low and intermediate water contents has been reported by many authors: Donovan (1979) for potato starch, Biliaderis et al. (1986) for rice starch, Garcia et al.(1996) for manioc, and Barron, Buléon, Colonna \& Della Valle (2000) for smooth pea. Different interpretations have been advanced to explain this phenomenon. In excess of water (above $70 \%$ ), only one single gelatinization endotherm occurs over a constant temperature range, reflecting the loss of semicrystalline order; the melting of starch crystallites is supposed to be facilitated by the swelling of the amorphous region surrounding the crystallites (Donovan, 
1979). At intermediate water contents between 70 and 35\%, only part of the crystallites melt which explains the decrease of the gelatinization enthalpy whereas the peak temperature remains constant. At water contents lower than $40 \%$ the remaining crystallites melt at higher temperature according to the Flory theory of polymer-diluent interactions. This theory has been successfully applied for water volume fraction lower than $70 \%$; it allows to estimating the melting temperature of the last crystallite as function of the moisture content. The melting term is then preferred to describe the thermal transitions under such conditions of heating at low or intermediate water contents. Biliaderis et al. (1986) however showed that starch, as a semicrystalline polymer, may undergo reorganizations in the amorphous phase and in the remaining crystallites during heating in the calorimeter; this means partial melting followed by recrystallisation processes and subsequent melting during DSC. The results of the DSC characteristics as a function of the moisture content will be used in order to explain the occurrence of the gelatinization process during the DIC treatment.

\subsection{EFFECT OF DIC HYDROTHERMAL TREATMENT}

\subsubsection{Thermal transition characteristics}

All the thermal characteristics of DIC treated samples were measured at a water content of $90 \%$ for which only one endotherm of gelatinization is expected. The DSC thermograms are presented in Fig. 2: pressure levels varied from 1 bar (Fig.2-a) to 2 bar (Fig.2-b) and 3 bar (Fig.2-c) for different treatment times. Table 2 summarises the transition temperatures: onset $\left(T_{0}\right)$, peak $\left(T_{p}\right)$, and temperature range $(R)$ calculated as $2\left(T_{p}-T_{0}\right)$, the enthalpies of gelatinization of native and DIC treated maize starch and the residual enthalpy ratio (RE). The DSC parameters of untreated starch were: $\mathrm{T}_{0}=63.1{ }^{\circ} \mathrm{C}, \mathrm{T}_{\mathrm{p}}=69.6{ }^{\circ} \mathrm{C}, \mathrm{R}=13{ }^{\circ} \mathrm{C}$ and $\Delta \mathrm{H}=11.4 \mathrm{~J} / \mathrm{g}$. These values are comparable to the temperatures and enthalpy of gelatinization reported by many authors for standard maize starch (Cooke \& Gidley, 1992, Hoover et al., 1996; Lim et al., 2001; Singh, Inouchi \& Nishinari, 2006). After the DIC treatment, the 
gelatinization endotherms were shifted towards higher temperatures, the effect on $\mathrm{T}_{0}$ and $\mathrm{Tp}$ being larger for higher pressures and longer times (Fig. 2). The gelatinization temperatures $\left(\mathrm{T}_{0}, \mathrm{~T}_{\mathrm{p}}\right)$ increased with the increase of processing pressure. At approximately $10 \mathrm{~min}$ of processing time, $\mathrm{T}_{0}$ and $\mathrm{T}_{\mathrm{p}}$ were $65.7 / 72.3{ }^{\circ} \mathrm{C}, 68.8 / 73.6{ }^{\circ} \mathrm{C}$, and $74.8 / 79.8{ }^{\circ} \mathrm{C}$ for pressure levels of 1, 2 and 3 bar, respectively (63.1/69.6 for native starch). Processing time also caused an increase of the transition temperatures. At a fixed pressure of 2 bars, $T_{0}$ and $T_{p}$ varied from 64.7/70.7 ${ }^{\circ} \mathrm{C}, 70.7 / 75.5^{\circ} \mathrm{C}, 72.7 / 77.2^{\circ} \mathrm{C}$, to $76.2 / 80.3{ }^{\circ} \mathrm{C}$, as the processing times increased from 2, 30 and 60 to $180 \mathrm{~min}$.

The modifications of the transition temperatures are closely related to the combined effect of processing pressure and treatment time. These parameters modify the moisture content of the starch granules during the process, moisture content playing a very important role to induce melting of starch crystallites. Water intake during the DIC treatment is a kinetic phenomenon as was demonstrated by Zarguili et al. (2008). They showed that, for standard maize starch, the moisture content of starch granules increased during the process with processing time, due to the absorption of accumulated steam. Fig. 3 shows the thermal characteristics of DIC treated maize starch at different processing times and moisture contents. The significant modifications of the thermal characteristics started at about $0.5 \mathrm{~min}$ at $3 \mathrm{bar}, 10 \mathrm{~min}$ at 2 bar and 60 min at 1 bar (Fig 3-a and 3-c). The initial moisture content of starch is generally about 11\%. During the process, the moisture content reaches the equilibrium after a given time which depends on the level of the processing pressure. At the pressures of 1 and $2 \mathrm{bar}$, the equilibrium moisture content was $15 \%$ and $20 \%$ (wet basis) and was reached after 30 and 60 min of processing, respectively. At 3 bar the moisture content was $17 \%$ after 20 min of treatment but could not be measured for longer treatment times due to the formation of compact lumps of starch powder. When experiments are performed below the equilibrium conditions, the moisture content (and hence the thermal transitions) depends on the processing 
time for a fixed pressure level. All the water contents are below the values for which gelatinization is expected according to the Table 1 (i.e. below 35\%). Consequently the transition of starch will be referred to as melting during the DIC process.

Hoover et al. (1996) observed an increase of gelatinization temperatures for standard maize starch after HMT treatment at moisture content of $30 \%$ and temperature of $100{ }^{\circ} \mathrm{C}$ during 16 hours. $\mathrm{T}_{0}$ and $\mathrm{T}_{\mathrm{P}}$ of native maize starch increased from 59 and $66{ }^{\circ} \mathrm{C}$ to 62 and $71{ }^{\circ} \mathrm{C}$ respectively after HMT treatment. After HMT treatment of maize starch $\left(120{ }^{\circ} \mathrm{C}, 25-30 \%\right.$ of water content and 1 hour) Lim et al. (2001) observed no significant change in $T_{0}$ whereas $T_{p}$ and $\mathrm{T}_{\mathrm{c}}$ (conclusion temperature) increased substantially. According to Biliaderis et al. (1986) and Gunaratne et al. (2002), the melting temperatures $\left(T_{0}, T_{P}, T_{c}\right)$ of the starch crystallites might be controlled indirectly by the swelling or mobility of the surrounding amorphous region. One of the effects of the heat-moisture treatment would be to promote the association between amylose chains and amylose-lipids within the amorphous region (Hoover et al., 1996) thus decreasing the destabilizing effect of the amorphous region upon melting of the starch crystallites.

DIC treatment causes an increase of the transition temperatures as HMT treatment, but has an opposite effect on the gelatinization temperature range $(\mathrm{R})$, calculated as $2\left(\mathrm{~T}_{\mathrm{p}}-\mathrm{T}_{0}\right)$; $\mathrm{R}$ decreased from $13{ }^{\circ} \mathrm{C}$ for native starch, to $11.6,9$ and $10{ }^{\circ} \mathrm{C}$ for DIC treated maize starch at 1 bar/60 min, 2 bar/60 min and 3 bar/10 min, respectively; severe DIC conditions (2 or 3 bar, Fig. 3-b) reducing more the width of the gelatinization endotherms. On contrary, Hoover et al. (1996) and Lim et al. (2001) noted a broadening of the temperature range of about $4-6{ }^{\circ} \mathrm{C}$ for standard maize starch. The narrowing of the temperature range after DIC treatment seems similar to the one observed by Stute (1992) after annealing of potato starch. According to Hublin (1994), R reflects the degree of cohesion between crystallites; when R decreases a stronger cohesion may exist between crystallites. Fredriksson, Silverio, Andersson, Eliasson 
\& Aman (1998), Gunaratne et al. (2002) have also suggested that the gelatinization temperature range gives an indication on the quality and heterogeneity (in size or stability) of crystallites. The higher R exhibited by native maize starch (Table 2) can be attributed to its broader range of crystallites stability, and the narrower temperature range exhibited by DIC treated starch suggests the presence of crystallites of more homogenous stability (or more homogenous size). We suppose that the DIC treatment first allowed the fusion of crystallites of low cohesion (or low size), which melt at lower temperature and a reinforcement of the interactions between the remaining crystallites chains. Consequently, the residual structure after treatment might contain crystallites with a greater stability (or greater size).

The DIC treatment decreased gradually the enthalpy of gelatinization as processing pressure and time increased (Fig. 2) and (Table 2). The gelatinization enthalpy decreased from 11.4

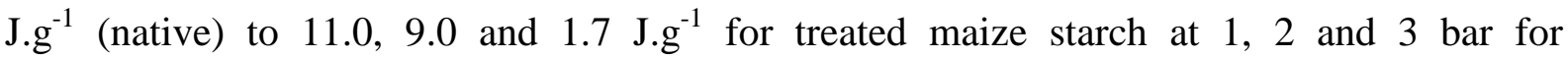
approximately $10 \mathrm{~min}$. At a fixed pressure level, the enthalpy decreased with processing time (Fig. 3-c); the effect of treatment time being reinforced at high pressure. By considering the residual enthalpy (Table 2), the standard maize starch treated at 1 and 2 bar for $180 \mathrm{~min}$ reached a residual enthalpy ratio of $69.3 \%$ and $36.8 \%$, whereas 20 min of DIC treatment were sufficient to melt totally starch at 3 bar. The effect of the HMT treatment on the residual enthalpy of standard maize starch depends on the treatment conditions: the gelatinization enthalpy may remain unchanged (Hoover et al., 1996) or decrease (Lim et al., 2001; Miyoshi, 2001; Vermeylen et al., 2006). Loisel et al. (2006) already showed by using response surface methodology that the steam pressure level, and therefore the temperature, had a more significant effect than the processing time; the temperatures associated with the pressure levels were $100{ }^{\circ} \mathrm{C}, 122{ }^{\circ} \mathrm{C}$ and $135{ }^{\circ} \mathrm{C}$ for pressures of 1,2 and 3 bar respectively. Fig. 3-d shows the reduction of enthalpy $(\Delta \mathrm{H})$ of residual structure of treated maize starch as function of moisture content for three pressure levels. As already mentioned, the moisture contents at 
equilibrium are $15 \%, 20 \%$ and $17 \%$ at $1\left(100^{\circ} \mathrm{C}\right), 2\left(122^{\circ} \mathrm{C}\right)$ and 3 bars $\left(135^{\circ} \mathrm{C}\right)$ reached after 30, 60 and $20 \mathrm{~min}$, respectively. For these moisture contents the temperature that have to be reached to initialize the melting processus $\left(\mathrm{T}_{0}\right)$ according to Table 1 are: $137{ }^{\circ} \mathrm{C}, 133^{\circ} \mathrm{C}$ and about $140{ }^{\circ} \mathrm{C}$ for 1,2 and 3 bar respectively: these temperatures did not occur during the DIC process for these pressures. This means that under the moisture and temperature conditions encountered during the DIC process, the melting of the most stable crystallites should not occur; but the melting may concern the smallest or the least cohesive crystallites, or those which have the more defects; the gelatinization process as previously described is also excluded. This indicates that starch reorganization (melting and recrystallisation) within the granule probably took place during the DIC process as was stated from the DSC characteristics, despite low temperatures and moisture contents.

It is also possible that the moisture content may have increased locally to higher values than the ones measured, enhancing thus the thermal transitions. The strong effect of the moisture content (in the range 18-20\%) on the reduction of the enthalpy has been clearly attested by Adebowale \& Lawal (2003), while Vermeylen et al. (2006) observed that the highest temperatures of treatment and moisture contents of hydrothermally treated potato starch provoked the largest changes on gelatinization enthalpy.

\subsubsection{Formation of amylose lipid-complexes and $X$ ray diffraction}

Figure 4 shows the DSC thermograms of native and DIC treated starch. These thermograms exhibit two endotherms: the first endotherm, at lower temperature, corresponds to the gelatinization-melting of crystalline lamellae of intact structure of native starch and residual structure of DIC treated starch as previously discussed. The second endotherm at higher temperature corresponds to the disintegration or melting of amylose-lipid complexes. Amylose-lipid complexes are known to present endothermic transitions at temperature above the gelatinization temperature range of starch (Eliasson, 1988); the enthalpy reflects the 
relative amount of formed complexes in the sample (Tufvesson, Wahlgren \& Eliasson, 2003). The thermal characteristics of amylose-lipid complexes are given in Table 3. For native starch and starch treated under mild DIC conditions (from 1bar/10 min to $2 \mathrm{bar} / 15 \mathrm{~min}$ ) the peak temperatures and the enthalpy values of the complex remained constant at $94.7^{\circ} \mathrm{C}$ and about $0.2 \mathrm{~J} / \mathrm{g}$ respectively. From $2 \mathrm{bar}$ and $15 \mathrm{~min}$ an increase of the transition temperatures and the enthalpy of melting of the amylose-lipid complex of maize starch clearly appeared; this tendency was reinforced as the DIC conditions, mainly the pressure level/or temperature, progressively increased. Transition temperatures $\left(\mathrm{T}_{0} / \mathrm{T}_{\mathrm{p}}\right)$ increased from $88.5 / 94.7{ }^{\circ} \mathrm{C}$ to

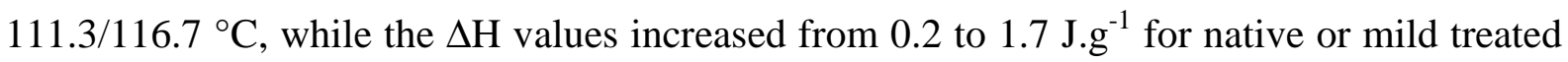
starch to starch treated at $3 \mathrm{bar} / 15 \mathrm{~min}$, respectively. Lim et al. (2001) also observed an increase of the amylose-lipid complex formation for standard maize starch induced by the HMT treatment (at $120^{\circ} \mathrm{C}, 1$ hour and 25 or $30 \%$ moisture content). Amylose-lipid complexes rarely exist in native cereal starches but are usually formed upon heating during industrial drying or during gelatinization of starch. According to the transition temperatures and enthalpies values of Table 3, it seems that different kinds of amylose-lipid complexes are encountered during the DIC treatment: from $1 \mathrm{bar} / 10 \mathrm{~min}$ to $2 \mathrm{bar} / 15 \mathrm{~min}$, the complexes induced by the gelatinization of starch during the DSC analysis might prevail, as it occurs for native starch, whereas for higher time/pressure conditions the complexes might be promoted by the HMT treatment. According to Buléon, Colonna, Planchot and Ball (1998) the amylose chains are involved either in isolated inclusion complexes or in crystalline packing arrangements; only this later structure can be detected by X-ray diffraction analysis in the form of Vh-type diffraction diagram. The occurrence of this structure induced by the DIC treatment has to be confirmed by the X-ray diffraction analysis.

Figure 5 shows the X-ray diffraction patterns of native and DIC treated maize starch. An Atype X-ray diffraction pattern with peaks centred at approximately $15^{\circ}, 17.1^{\circ}, 18^{\circ}$ and $23^{\circ}$ 
(20) typical for cereal starches (Zobel, 1964; Imberty, Buléon, Tran \& Perez, 1991) is shown for native maize starch. This A-type crystalline pattern was conserved for DIC treated starch at 1 bar for any processing time, and no significant differences in the relative crystallinity value with native starch were observed (Table 3). The reduction in relative crystallinity became significant at a pressure of 2 bar/15 min; the relative crystallinity was 27 and $22 \%$ for processing time of 15 and $60 \mathrm{~min}$, respectively. The A-type crystalline pattern was progressively reduced with the increase of processing pressure ( $\geq 2$ bars). New peaks appeared at $7.5^{\circ}, 13^{\circ}$ and $19.5^{\circ}(2 \theta)$, characteristics of the $\mathrm{V}_{\mathrm{h}}$-type which revealed the formation of amylose-lipid complexes in starch (Eliasson, 1988; Biliaderis \& Galloway, 1989). At severe DIC conditions (3 bar/15 min), the typical peaks of A-type X-ray diffraction pattern were almost replaced by the ones of the $\mathrm{V}_{\mathrm{h}}$-type pattern. The resolution and intensity of the new peaks attest that amylose-lipid complexes can reorganize in a crystalline packing as a result of the DIC treatment, as suggested before.

The amylose-lipid complex formation is affected by several factors: the more important are the temperature of the process and the water content (Le Bail, Bizot, Ollivon, Keller, Bourgaux \& Buléon, 1999). These authors observed a $\mathrm{V}_{\mathrm{h}}$-type diffraction pattern around 110$115^{\circ} \mathrm{C}$ after heating maize starch in excess of water ( $65 \%$ moisture content). They suggested that the important leaching of amylose enables the extra-granular crystallization of amylose and lipid. At low moisture contents, Le Bail et al. (1999) showed that the treatment enhanced the formation of the amylose-lipid complex inside the swollen granules because of the reduction of amylose solubilization. It can be then concluded that the DIC treatment induces the formation of amylose-lipid complexes inside the starch granules, due to the low moisture content (up to 20\%) encountered during the process.

\subsubsection{Structural characteristics}


Microscopic observations under polarized light of native and treated maize starch at different pressures are presented in Fig. 6. The native (Fig. 6a) and DIC treated starch at low pressure (1 bar) displayed a clear polarization cross at the hile of the granule (Fig. $6 \mathrm{~b}$ and $6 \mathrm{c}$ ), confirming the preservation of the crystallinity. DIC treated starches at 2 bar mainly remained birefringent even for treated sample at $2 \mathrm{bar} / 60 \mathrm{~min}$ (Fig. 6e), for which the absence of polarization cross on some granules started to be observed. At 3 bars $/ 0.5$ min the intensity of the birefringence of treated starch slightly decreased but the polarization cross remained clearly for numerous starch granules (Fig. 6f). At the same pressure for higher processing time (15 $\mathrm{min}$ ), the birefringence of the starch granules totally disappeared (Fig. 6g), this result confirmed the almost total melting of starch (9.6\% residual enthalpy ratio) observed by DSC and $\mathrm{X}$ ray diffraction. Starch granules were also observed in light microscopy (not presented) that revealed no modification of the size and shape of the DIC treated granules in the dry state. Table 4 presents the size characteristics of starch granules before (in cold water) and after pasting in the Brabender Viscograph $\left(95^{\circ} \mathrm{C}-20 \mathrm{~min}\right)$. As already mentioned by Loisel et al. (2006), the median diameter and the swelling ratio of DIC treated starch increased in cold water, with pressure level and processing time; the size distribution (span) also broadened that might be due for the highest pressure/time conditions to aggregation of starch granules. After pasting the reverse tendency could be observed (except at 1 bar/10 min), that means a progressive disruption of the starch granules as an effect of the DIC treatment. This disruption of starch granules was confirmed by microscopic observations and resulted in a dramatic decrease of the viscosity of the paste (Loisel et al., 2006). The increase of the swelling ratio in cold water may be ascribed to the loss of crystallinity as already discussed that enhances the penetration of water within the starch granules. Upon heating, the decrease of the swelling power has been mentioned by Hoover et al. (1996) and Maruta et al. (1994) on pasted standard maize starch treated by HMT $\left(100^{\circ} \mathrm{C}\right.$, 1hour) and RP-HMT (reduced-pressurized 
HMT up to $124^{\circ} \mathrm{C}$ ) respectively. Hoover et al. (1996) attributed this decrease to the interaction between amylopectin chains.

\section{Conclusion}

This study demonstrates that the DIC hydrothermal process of starch leads to modifications that are in most cases in agreement with on the ones observed with HMT treatment: the gelatinization of standard maize starch treated by DIC occurs at higher temperatures and requires lower enthalpy compared to untreated starch. But on the opposite, a narrower gelatinization temperature range $(\mathrm{R})$ is observed for DIC treated maize starch that can be compared to the one reported with the annealing treatment. This result suggests that the treatment firstly allows the melting of most fragile crystallites (of lowest cohesion) or the smallest ones which require less energy to melt. Consequently, the residual structure contains crystallites with a greater stability or size, as well as greater homogeneity (of stability or size). This new organization is linked with the formation of crystalline arrangements of amyloselipid complexes inside the starch granules owing to the enhanced mobility of amylose chains during the treatment. All the modifications of the crystalline structure are enhanced by the temperature and moisture content encountered during the DIC treatment (related to pressure and time of treatment). It is worth noting that the starch reorganization of the structure occurs without any swelling of starch granules and leaching of amylose during the treatment; except may be for the highest conditions of the treatment for which the starch granules become sticky. All these structural modifications result in a progressive decrease of the melting enthalpy of starch with the intensity of the treatment. This may be related to the greater accessibility to water observed during swelling in cold water and consequently to an increase of the susceptibility to further physical or enzymatic treatment of the starch suspensions. 
Acknowledgements: the authors thank B. Pontoire for excellent technical assistance concerning the X-ray analysis. 


\section{References}

Adebowale, K.O., \& Lawal, O. S. (2003). Microstructure, physicochemical properties and retrogradation behaviour of Macuna bean (Macuna pruriens) starch on heat moisture content. Food hydrocolloids, 17, 265-272.

Allaf, K., Louka, N., Bouvier, J.-M., Parent, F., Forget, M., 1993. Procédé de traitement de produits biologiques en vue de la modification de leur texture, installations pour la mise en œuvre d'un tel procédé et produits ainsi réalisés. French patent, n ${ }^{\circ} 93$ 09720. International extension no PCT/FR94/00975.

Barron, C., Buléon, A., Colonna, P., \& Della Valle, G. (2000). Structural modifications of low hydrated pea starch subjected to high thermomechanical processing. Carbohydrate Polymers, 43,171-181.

Biliaderis, C. G. (1991). The structure and interactions of starch with food constituents. Canadian Journal of Physiology and Pharmacology, 69, 60-78.

Biliaderis, C. G., \& Galloway, G. C. (1989). Crystallization behaviour of amylose complexes: structure-property relationships. Carbohydrate research, 189, 31-48.

Biliaderis, C. G., Maurice, T. J., \& Vose, J. R. (1980). Starch gelatinization phenomena studied by differential scanning calorimetry. Journal of Food Science, 45, 1669-1680.

Biliaderis, C. G., Page C. M., Maurice T. J., \& Juliano B.O. (1986). Thermal characterization of rice starches: a polymeric approach to phase transitions of granular starch. Journal of Agricultural and Food Chemistry, 34, 6-14.

Buléon, A., Bertrand, D. (1982). Relative influence of water sorption properties and cristallinity of $\mathrm{NaOH}$ treated cellulose on its susceptibility of enzymatic microbial degradation. Journal of Applied Biochemistry, 4, 218.

Buléon, A., Colonna, P., Planchot, V., \& Ball, S. (1998). Starch granules: structure and biosynthesis. International Journal of Biological Macromolecules, 23, 58-112.

Collado. L. S., \& Corke, H. (1999). Heat-moisture treatment effects on sweet potato starches differing in amylose content. Food chemistry, 65. 329-346.

Cooke D., \& Gidley, M. J. (1992). Loss of cryistallinne and molecular order during starch gelatinization: origin of the enthalpic transition. Carbohydrate Research, 227, 13-112.

Cruz-Orea, A., Pitsi, G., Jamee, P., \& Thoen, J. (2002). Phase transitions in the starch-water system studied by adiabatic scanning calorimetry. Journal of Agricultural and Food Chemistry, 50, 1335-1344.

Donovan, J. W. (1979). Phase transitions of the starch-water system. Biopolymers, 18, 263275.

Eliasson, 1988. A.-C. Eliasson, Physical and chemical characteristics of legume starches. Animal Plant Sci, 1, 89-94. 
Fredriksson, H., Silverio, J., Andersson, R., Eliasson, A. -C., \& Aman, P. (1998). The influence of amylose and amylopectin characteristics on gelatinization and retrogradation properties of different starches. Carbohydrate Polymers, 35, 119-134.

Garcia, V., Colonna P., Lourdin, D., Buléon, A., Bizot, H., \& Ollivon, M. (1996). Thermal transitions of cassava starch at intermediate water contents. Journal of Thermal Analysis, 47, 1213-1228.

Gunaratne, A., \& Corke, H. (2007). Influence of unmodified cycloheptaamylose ( $\beta$ cyclodextrin) on transition parameters of amylose-lipid complex and functional properties of starch. Carbohydrate Polymers, 68, 226-234.

Gunaratne, A., \& Hoover, R. (2002). Effect of heat-moisture treatment on the structure and physical properties of tuber and root starches. Carbohydrate Polymer, 49, 425-437.

Hoover, R., \& Manuel. H. (1996). Effect of heat-moisture treatment on the structure and physicochemical properties of normal maize. waxy maize. dull waxy maize and amylomaize V starches. Journal of Cereal Science, 23. 153-162.

Hoover, R., \& Vansanthan, T. (1994). Effect of heat-moisture treatment on the structure and physicochemical properties of cereal. tuber. and legume starches. Carbohydrate Research, 252. 33-53.

Hoseney, R. C., Zeleznak, K., \& Lai, C. S. (1986). Wheat gluten: A glassy polymer. Cereal Chemistry, 63, 285-286.

Hublin, L. (1994). Influence des caractéristiques structurales des amidons natifs sur leur reactivité chimique. PhD dissertation, Université de Nantes. France.

Imberty, A., Buléon, A., Tran, V., \& Perez, S. (1991). Recent advances in knowledge of starch structure. Starch/Stärke, 43, 375-384.

Jacobs, H., Mischenko, N., Koch, M. H. J., Eerlingen, R. C, Delcour. J. A., \& Reynaers, H. (1998). Evaluation of the impact of annealing on gelatinisation at intermediate water content of wheat and potato starches: A differential scanning calorimetry and small angle X-ray scattering study. Carbohydrate Research. 306, 1-10.

Krueger, B. R., Knutson, C.A, Inglett, G. E., \& Walke, C. E. (1987). A differential scanning calorimetry study on the effect of annealing on gelatinization behavior of corn starch. Journal of Food Science, 52, 715-718.

Kulp, K., \& Lorenz, K. (1981). Heat-moisture treatment of starches. I- Physicochemical properties. Cereal Chemistry, 58. 46-48.

Le Bail, P., Bizot, H., Ollivon, M., Keller, G., Bourgaux, C., \& Buléon, A. (1999). Monitoring the crystallization of amylose-lipid complexes during maize starch melting using synchrotron X-ray diffraction. Biopolymers, 50, 99-110.

Lim, S. T., Chang, E. H., \& Chung, H. J. (2001). Thermal transition characteristics of heatmoisture treated corn and potato starches. Carbohydrate Polymers, 46, 107-115. 
Loisel, C., Maache-Rezzoug, Z., Esneault, C., \& Doublier, J. L. (2006). Effect of hydrothermal treatment on the physical and rheological properties of maize starches. Journal of Food Engineering, 73, 45-54.

Maache-Rezzoug, Z., Allaf, K. (2005). Study of the effect of hydrothermal process conditions on pasta quality. Journal of Cereal Science. 41, 267-275.

Maruta, I., Kurahashi, Y., Takayano, R., Hayashi, K., Yoshino, Z., Komaki, T., \& Hara, S. (1994). Reduced-pressurized heat-moisture treatment. A new method for heat-moisture treatment of starch. Starch/Stärke. 46, 177-181.

Miyoshi, E. (2001). Effects of heat-moisture treatment and lipids on gelatinization and retrogradation of maize and potato starches. Cereal Chemistry, 79(1), 72-77.

NF V03-707. July 2000. Cereals and cereal products- Determination of moisture contentRoutine reference method.

Ratnayake, W. S., \& Jackson, D. S. (2007). New insight into the gelatinization process of native starches. Carbohydrate Polymers, 67 (4), 511-529.

Rezzoug, S. A., Maache-Rezzoug, Z., Mazoyer, J., \& Allaf, K. (2000). Effect of instantaneous controlled decompression process on hydration capacity of scleroglucan. Optimisation of operating conditions by response surface methodology. Carbohydrate polymers, 42 (1), 7384.

Sair, L. (1967). Heat-moisture treatment of starch. Cereal Chemistry. 44, 8-26.

Sair, L., \& Fetzer, W. R. (1944). Water sorption by starches, water sorption corn starch and commercial modifications of starches. Industrial and Engineering Chemistry, 36, 205-208.

Singh, N., Inouchi, N., \& Nishinari, K. (2006). Structural, thermal and viscoelastic characteristics of starches separated from normal, sugary and waxy maize. Food Hydrocolloids, 20, 923-935.

Stute, H. (1992). Hydrothermal modification of starches: the difference between annealing and heat-moisture treatment. Starch/Stärke, 44, 205-214.

Takaya, C. S., \& Nishinari, K. (2000). Thermal studies on the gelatinisation and retrogradation of heat-moisture treated starch. Carbohydrate Polymers, 41, 97-100.

Tester, R. F., Debon, S. J. J., \& Sommerville, M. D. (2000). Annealing of maize starch. Carbohydrate Polymers, 42, 287-299.

Tufvesson, F., Wahlgren, M., \& Eliasson, A-C. (2003). Formation of amylose-lipid complexes and effects of temperature treatment. Part 2. Fatty acids. Starch/Stärke, 55, 138149.

Tukomane, T., Leerapongnum, P., Shobsngob, S., \& Varavinit, S. (2007). Preparation and characterization of annealed-enzymatically hydrolyzed tapioca starch and the utilization in tableting. Starch/Stärke, 59(1), 33-45. 
Vermeylen, R., Goderis, B., \& Delcour, J. A. (2006). An X-ray study of hydrothermally treated potato starch. Carbohydrate Polymer, 64, 364-375.

Wakelin, J. H., Virgin, H. S., \& Crystal, E. (1959). Development and comparison of two Xray methods for determining the crystallinity of cotton cellulose. Journal of Applied Physics, $30,1654-1662$.

Zarguili, I., Maache-Rezzoug, Z., Loisel, C., \& Doublier, J.-L. (2006). Influence of DIC hydrothermal process conditions on the gelatinization properties of standard maize starch. Journal of Food Engineering, 77 (3), 454-461.

Zarguili, I., Maache-Rezzoug, Z., Loisel, C., \& Doublier, J.-L. (2008). A mathematical model to describe the change of moisture distribution in maize starch during DIC hydrothermal treatment. International Journal of Food Science and Technology, in press.

Zobel H. F. (1964). X-ray analysis of starch granules. Methods in Carbohydrate Chemistry, Acad. Press, 4, 109-113. 


\section{Figures captions}

Figure 1. DSC thermograms of native standard maize starch at different moisture contents (\%, wb). The volumic fraction of water is given in parentheses.

Figure 2. DSC thermograms for native and DIC treated standard maize starch at pressure levels of 1(a), 2 (b) and 3 bar (c) for various treatment times.

Figure 3. Thermal characteristics of DIC treated maize starch versus processing time at various pressure levels of 1, 2 and 3 bar: (a) peak temperature (Tp), (b) temperature range of gelatinization, (c) gelatinization enthalpy $(\Delta \mathrm{Hg})$. (d) gelatinization enthalpy $(\Delta \mathrm{Hg})$ versus moisture content.

Figure 4. DSC thermograms of native and DIC treated maize starch with the amylose-lipids complex.

Figure 5. X-ray diffraction patterns of native and DIC treated standard maize starch at different processing conditions.

Figure 6. Microscopic observations in polarized light of native standard maize starch (a) and DIC treated maize starch at $1 \mathrm{bar} / 10 \mathrm{~min}$ (b), 1 bar/60 min (c), 2 bar/15 min (d), 2 bar/60 min (e), $3 \mathrm{bar} / 0.5 \mathrm{~min}(\mathrm{f}), 3 \mathrm{bar} / 15 \mathrm{~min}(\mathrm{~g})$. 
Fig.1.

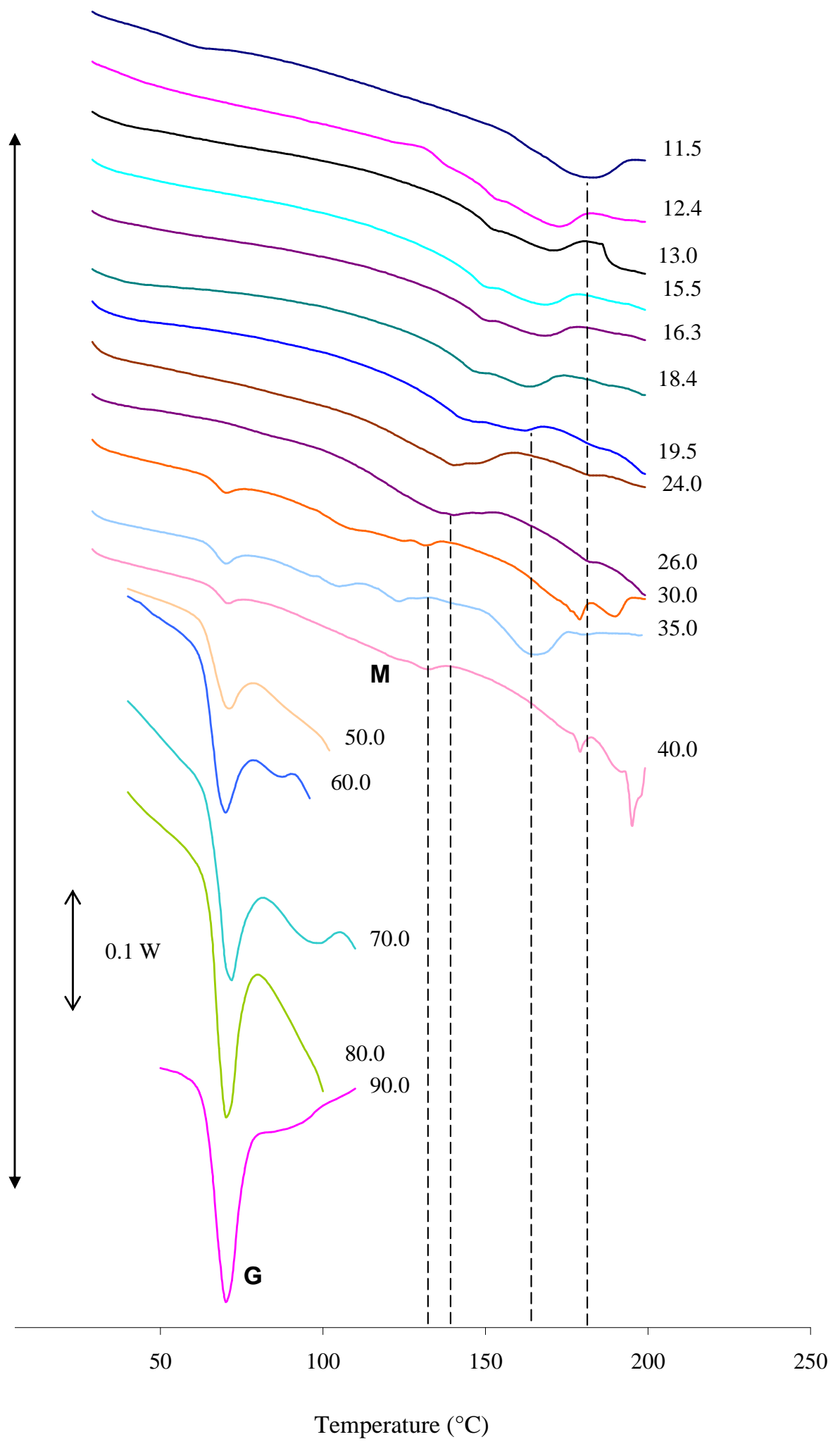


Fig. 2.

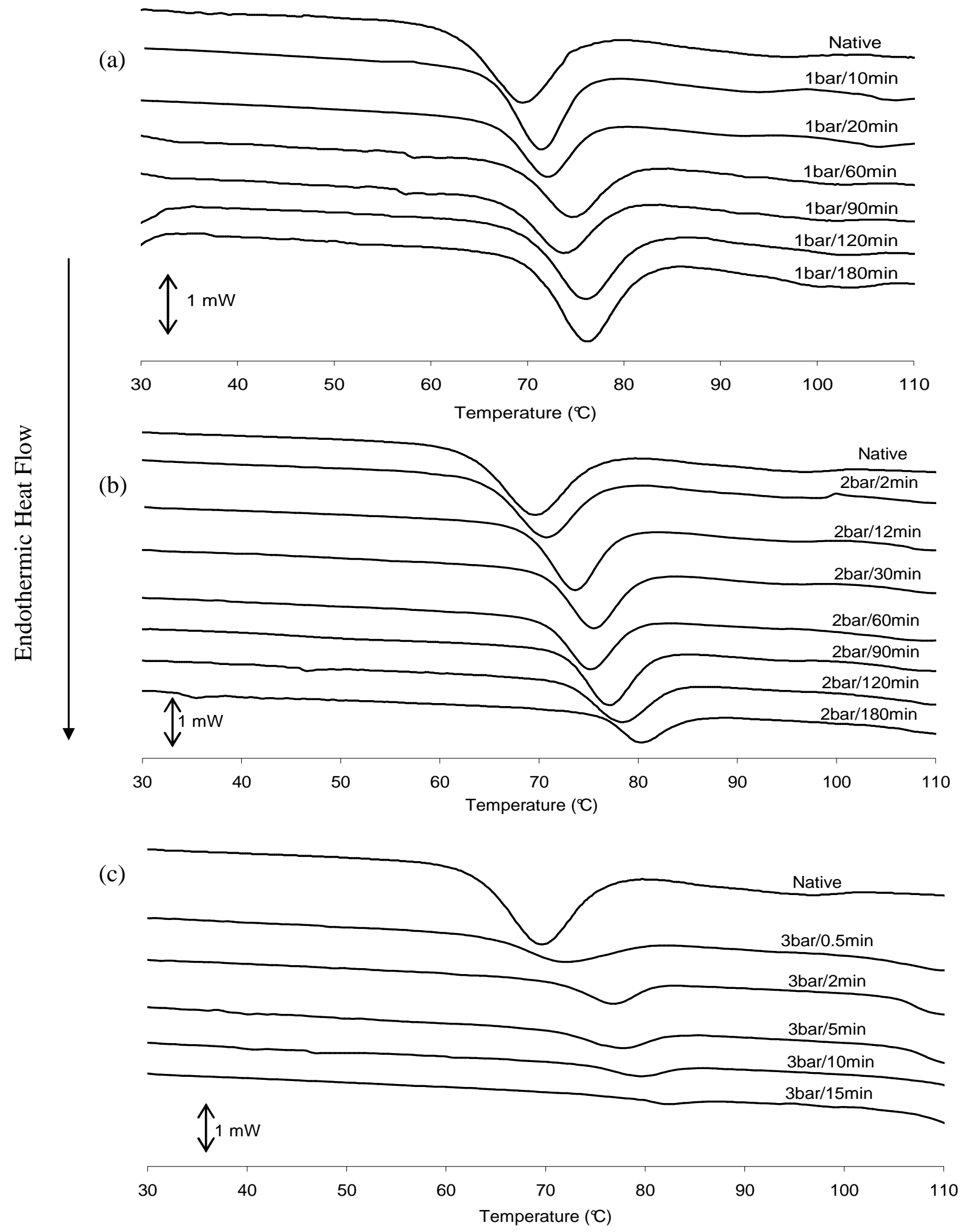


Fig. 3.
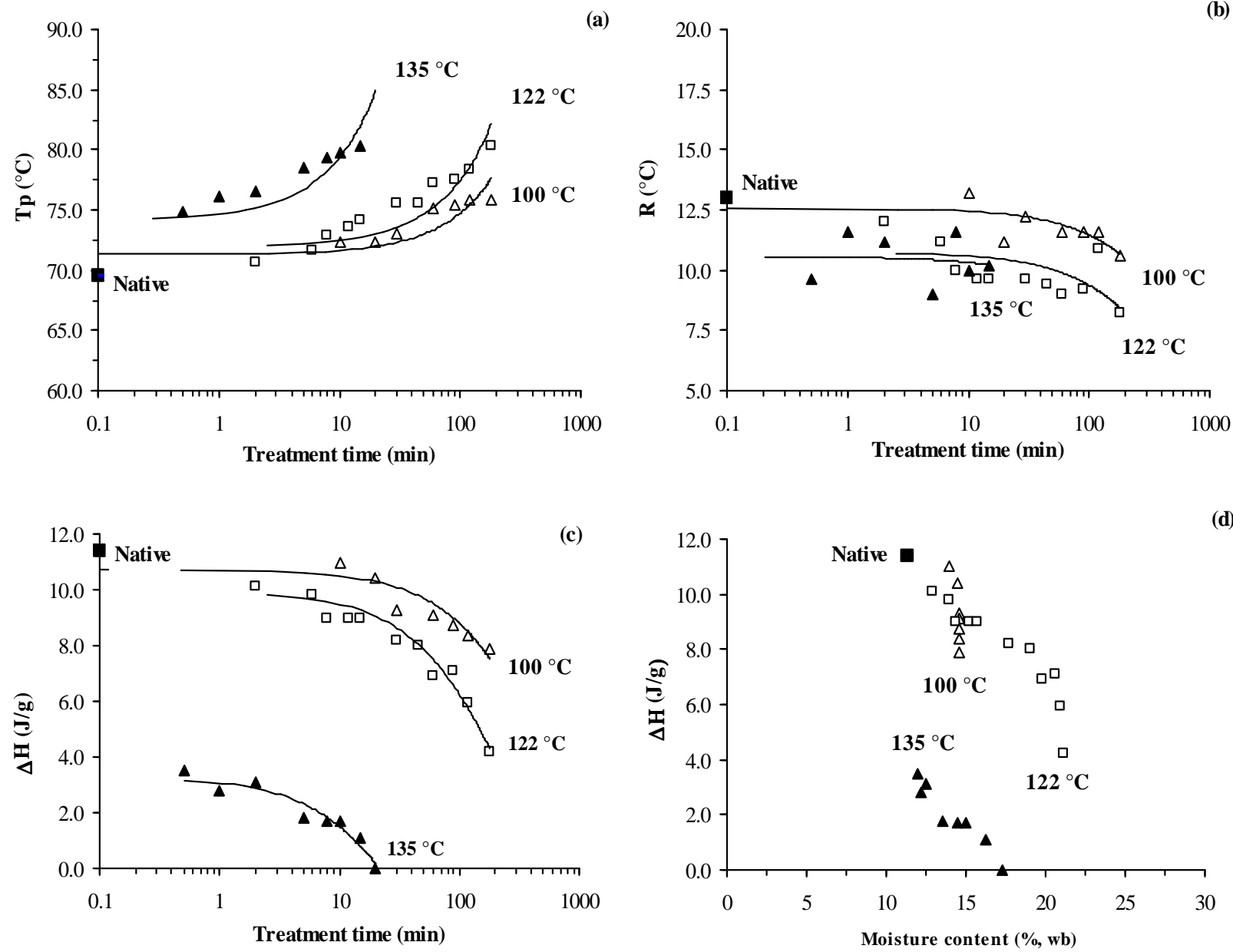
Fig. 4.

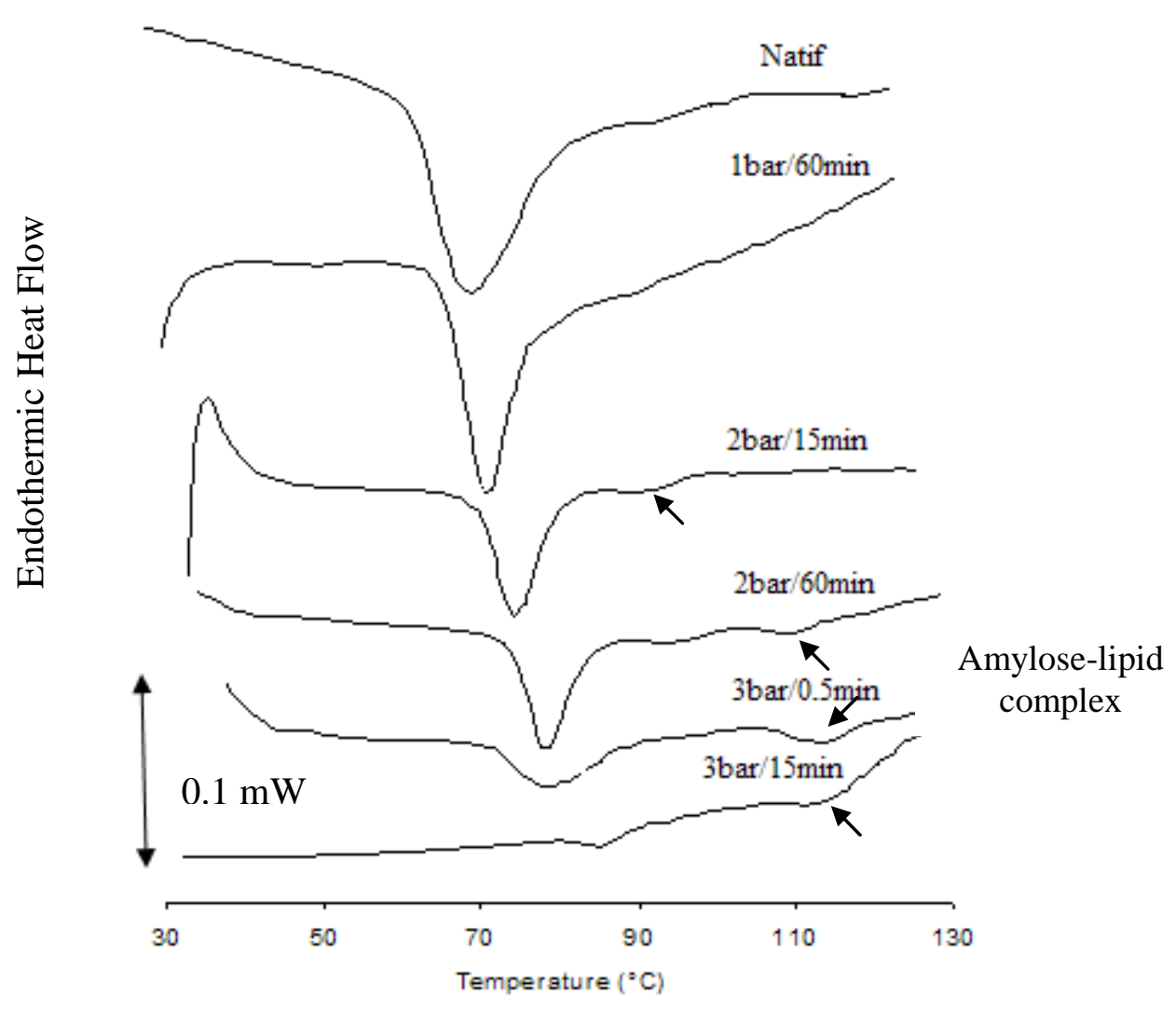


Fig. 5.

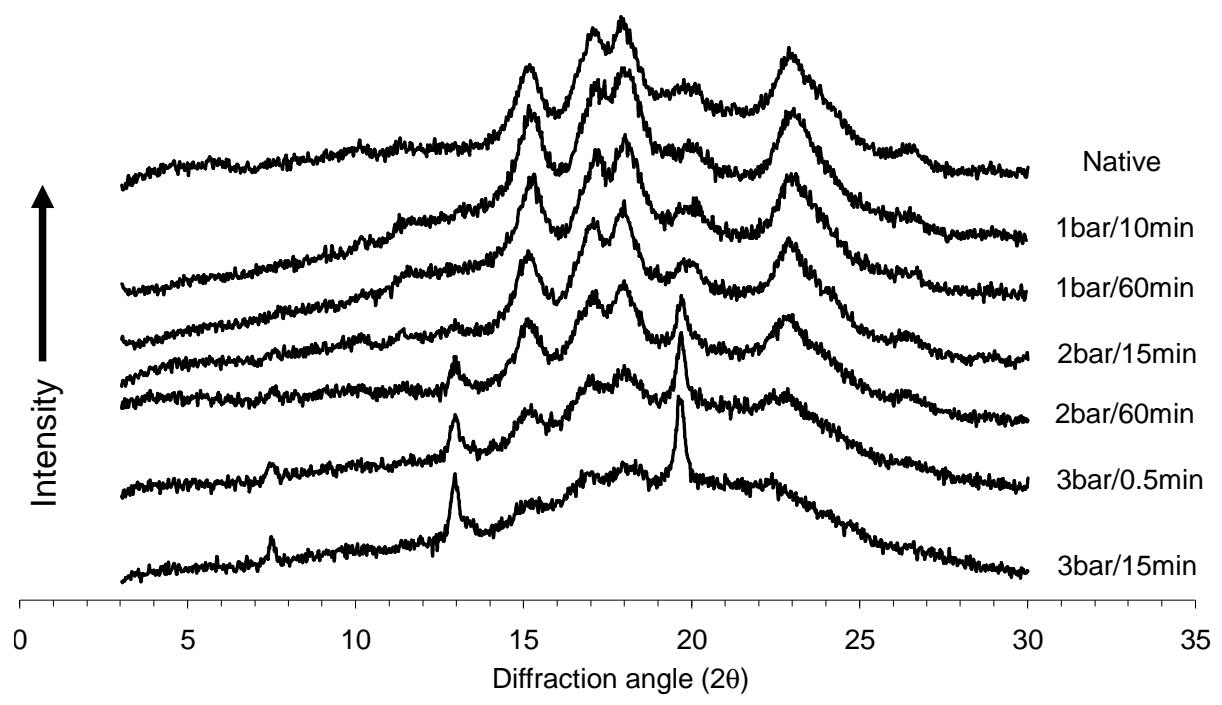


Fig. 6.
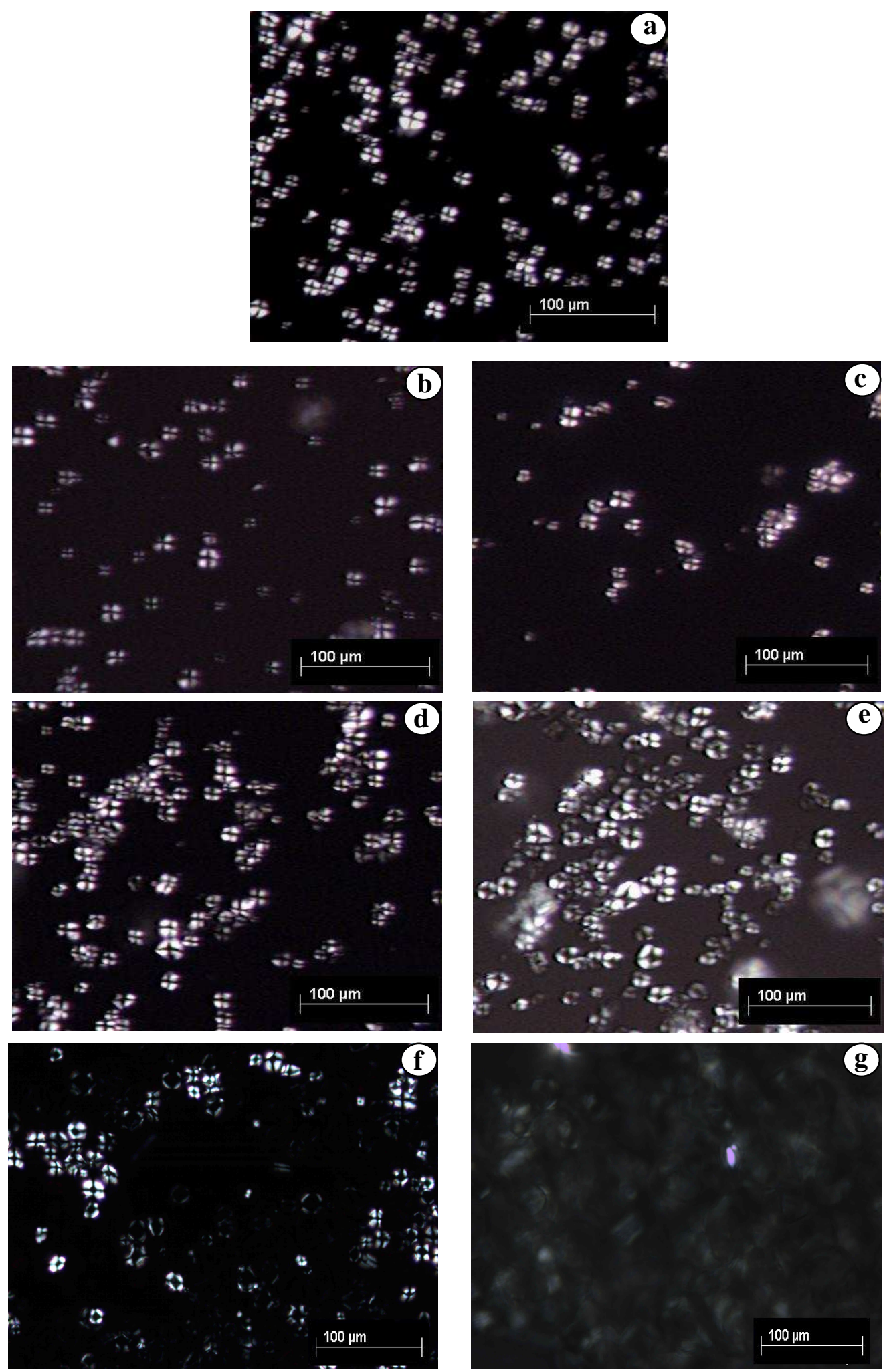
Table 1. DSC characteristics of native maize starch heated at different water contents.

\begin{tabular}{lllllll}
\hline $\begin{array}{l}\text { Moisture content } \\
\left(\%, \mathrm{w}_{\mathrm{b}}\right)\end{array}$ & \multicolumn{5}{c}{ Meling } & \multicolumn{5}{c}{ Gelatinization } \\
\cline { 2 - 7 } & $\mathrm{T}_{\mathrm{o}}\left({ }^{\circ} \mathrm{C}\right)$ & $\mathrm{T}_{\mathrm{p}}\left({ }^{\circ} \mathrm{C}\right)$ & $\Delta \mathrm{H}_{\mathrm{m}}\left(\mathrm{J} \cdot \mathrm{g}^{-1}\right)$ & $\mathrm{T}_{\mathrm{o}}\left({ }^{\circ} \mathrm{C}\right)$ & $\mathrm{T}_{\mathrm{p}}\left({ }^{\circ} \mathrm{C}\right)$ & $\Delta \mathrm{H}_{\mathrm{g}}\left(\mathrm{J}^{-1}\right)$ \\
\hline 11.5 & 154.8 & 183.7 & 10.1 & - & - & 0.0 \\
12.4 & 134.4 & 173.0 & 10.6 & - & - & 0.0 \\
13.0 & 141.5 & 171.0 & 6.4 & & & 0.0 \\
15.5 & 137.3 & 164.6 & 8.6 & - & - & 0.0 \\
16.3 & 140.6 & 168.9 & 7.3 & - & - & 0.0 \\
18.4 & 138.4 & 166.0 & 7.5 & & & 0.0 \\
19.5 & 132.9 & 162.1 & 6.1 & & & 0.0 \\
24.0 & 116.7 & 140.5 & 7.6 & - & - & 0.0 \\
26.0 & 116.7 & 140.4 & 6.6 & - & - & 0.0 \\
30.0 & 98.9 & 131.8 & 4.5 & 61.5 & 66.2 & 0.5 \\
35.0 & 85.0 & 123.5 & 2.5 & 61.4 & 67.0 & 1.3 \\
40.0 & - & - & 0.0 & 63.2 & 69.9 & 1.9 \\
50.0 & - & - & 0.0 & 64.0 & 70.3 & 5.7 \\
60.0 & - & - & 0.0 & 65.5 & 72.6 & 8.1 \\
70.0 & - & - & 0.0 & 65.7 & 70.5 & 9.8 \\
80.0 & - & - & 0.0 & 66.0 & 69.8 & 11.5 \\
90.0 & - & - & 0.0 & 65.9 & 69.6 & 11.4 \\
\hline
\end{tabular}

Values are means of triplicate determinations: $\mathrm{T}_{\mathrm{o}}$ : onset temperature; $\mathrm{T}_{\mathrm{p}}$ : peak temperature, $\Delta \mathrm{H}_{\mathrm{g}}$ : enthalpy of gelatinization and, $\Delta \mathrm{H}_{\mathrm{m}}$ : enthalpy of melting. 
Table 2. Thermal characteristics ${ }^{\mathrm{a}}$ of native and DIC treated maize starch at various steam pressures level and processing time.

\begin{tabular}{|c|c|c|c|c|c|c|}
\hline \multicolumn{2}{|l|}{ Sample } & \multicolumn{5}{|c|}{ Transition temperatures } \\
\hline DIC treatment ${ }^{\mathrm{b}}$ & $\begin{array}{l}\text { Moisture content } \\
\left(\%, \mathrm{w}_{\mathrm{b}}\right)\end{array}$ & $\mathrm{T}_{\mathrm{o}}\left({ }^{\circ} \mathrm{C}\right)$ & $\mathrm{T}_{\mathrm{p}}\left({ }^{\circ} \mathrm{C}\right)$ & $\mathrm{R}\left({ }^{\circ} \mathrm{C}\right)$ & $\Delta \mathrm{H}(\mathrm{J} / \mathrm{g})$ & $\mathrm{RE}(\%)$ \\
\hline Native & 11.4 & $63.1 \pm 0.4^{c}$ & $69.6 \pm 0.5$ & 13.0 & 11.4 & 100.0 \\
\hline $1 \mathrm{bar} / 10 \mathrm{~min}$ & 13.9 & $65.7 \pm 0.5$ & $72.3 \pm 0.4$ & 13.2 & 11.0 & 96.5 \\
\hline $1 / 20$ & 14.4 & $66.8 \pm 0.2$ & $72.4 \pm 0.4$ & 11.2 & 10.4 & 91.2 \\
\hline $1 / 30$ & 14.6 & $67.0 \pm 0.2$ & $73.1 \pm 0.3$ & 12.2 & 9.3 & 81.6 \\
\hline $1 / 60$ & 14.6 & $69.4 \pm 0.4$ & $75.2 \pm 0.6$ & 11.6 & 9.1 & 79.8 \\
\hline $1 / 90$ & 14.6 & $69.6 \pm 0.2$ & $75.4 \pm 0.4$ & 11.6 & 8.7 & 76.3 \\
\hline $1 / 120$ & 14.6 & $70.1 \pm 0.5$ & $75.9 \pm 0.7$ & 11.6 & 8.4 & 73.7 \\
\hline $1 / 180$ & 14.6 & $70.6 \pm 0.2$ & $75.9 \pm 0.4$ & 10.6 & 7.9 & 69.3 \\
\hline $2 \mathrm{bar} / 2 \min$ & 12.9 & $64.7 \pm 0.4$ & $70.7 \pm 0.6$ & 12.0 & 10.1 & 88.6 \\
\hline $2 / 12$ & 15.2 & $68.8 \pm 0.3$ & $73.6 \pm 0.5$ & 9.6 & 9.0 & 78.9 \\
\hline $2 / 30$ & 17.8 & $70.7 \pm 0.6$ & $75.5 \pm 0.7$ & 9.6 & 8.2 & 71.9 \\
\hline $2 / 60$ & 19.8 & $72.7 \pm 0.5$ & $77.2 \pm 0.4$ & 9.0 & 6.9 & 60.5 \\
\hline 2/90 & 20.6 & $72.9 \pm 0.6$ & $77.5 \pm 0.8$ & 9.2 & 7.1 & 62.3 \\
\hline $2 / 120$ & 20.9 & $73.0 \pm 0.5$ & $78.4 \pm 0.6$ & 10.9 & 6.0 & 52.6 \\
\hline $2 / 180$ & 21.2 & $76.2 \pm 0.7$ & $80.3 \pm 0.6$ & 8.2 & 4.2 & 36.8 \\
\hline $3 \mathrm{bar} / 0.5 \mathrm{~min}$ & 12.0 & $70.0 \pm 0.8$ & $74.8 \pm 0.8$ & 9.6 & 3.5 & 30.7 \\
\hline $3 / 2$ & 12.5 & $71.0 \pm 1.1$ & $76.6 \pm 0.9$ & 11.2 & 3.1 & 27.2 \\
\hline $3 / 5$ & 13.6 & $74.0 \pm 0.8$ & $78.5 \pm 1.0$ & 9.0 & 1.8 & 15.8 \\
\hline $3 / 10$ & 15.0 & $74.8 \pm 0.9$ & $79.8 \pm 0.7$ & 10.0 & 1.7 & 14.9 \\
\hline $3 / 15$ & 16.2 & $75.2 \pm 0.9$ & $80.3 \pm 0.8$ & 10.2 & 1.1 & 9.6 \\
\hline $3 / 20$ & 17.3 & - & - & - & 0.0 & 0 \\
\hline
\end{tabular}

${ }^{\mathrm{a}} \mathrm{T}_{\mathrm{o}}$ : onset temperature; $\mathrm{T}_{\mathrm{p}}$ : peak temperature; R: temperature range, calculated as $2\left(\mathrm{~T}_{\mathrm{p}}-\mathrm{T}_{\mathrm{o}}\right)$, ${ }^{\mathrm{b}}$ DIC treatment at pressure level of 1, 2 and 3 bar at various processing time.

Values are means of triplicate determinations \pm standard deviation. $\Delta \mathrm{H}$ : enthalpy of gelatinization; $0.5 \mathrm{~J} / \mathrm{g}$ is the mean absolute error (three repetitions) of $\Delta \mathrm{H}$. RE (\%): residual enthalpy ratio. 
Table 3. DSC characteristics ${ }^{\mathrm{a}}$ of starch gelatinization and amylose-lipid complex in native and DIC treated maize starch at various processing time and pressure levels of 1,2 and 3 bar.

\begin{tabular}{|c|c|c|c|c|c|c|c|c|c|}
\hline \multirow[b]{2}{*}{ Sample } & \multicolumn{4}{|c|}{ Gelatinization } & \multicolumn{3}{|c|}{ Amylose-lipid complex } & \multicolumn{2}{|c|}{$\begin{array}{l}\text { X-Ray } \\
\text { Diffractometry }\end{array}$} \\
\hline & $\mathrm{T}_{\mathrm{o}}\left({ }^{\circ} \mathrm{C}\right)$ & $\mathrm{T}_{\mathrm{p}}\left({ }^{\circ} \mathrm{C}\right)$ & $\mathrm{R}\left({ }^{\circ} \mathrm{C}\right)$ & $\begin{array}{l}\Delta \mathrm{H} \\
(\mathrm{J} / \mathrm{g})\end{array}$ & $\mathrm{T}_{\mathrm{o}}\left({ }^{\circ} \mathrm{C}\right)$ & $\mathrm{T}_{\mathrm{p}}\left({ }^{\circ} \mathrm{C}\right)$ & $\Delta \mathrm{H}(\mathrm{J} / \mathrm{g})$ & $\begin{array}{c}\text { Relative } \\
\text { cristallinity } \\
(\%)\end{array}$ & $\begin{array}{l}\text { X-ray } \\
\text { pattem }\end{array}$ \\
\hline Native & $63.1 \pm 0.4$ & $69.6 \pm 0.5$ & 13.0 & 11.4 & $88.5 \pm 0.2$ & $94.7 \pm 0.6$ & 0.18 & 31 & A type \\
\hline 1bar/10min & $65.7 \pm 0.5$ & $72.3 \pm 0.4$ & 13.2 & 11.0 & $88.5 \pm 0.2$ & $94.5 \pm 0.4$ & 0.18 & 31 & A type \\
\hline $1 \mathrm{bar} / 60 \mathrm{~min}$ & $69.4 \pm 0.4$ & $75.2 \pm 0.6$ & 11.6 & 9.1 & $88.1 \pm 0.3$ & $94.5 \pm 0.5$ & 0.20 & 30 & A type \\
\hline $2 \mathrm{bar} / 15 \mathrm{~min}$ & $69.4 \pm 0.5$ & $74.2 \pm 0.5$ & 9.6 & 9.0 & $88.5 \pm 0.3$ & $94.3 \pm 0.3$ & 0.37 & 27 & A type \\
\hline $2 \mathrm{bar} / 60 \mathrm{~min}$ & $72.7 \pm 0.5$ & $77.2 \pm 0.4$ & 9.0 & 6.9 & $103.5 \pm 0.5$ & $109.9 \pm 0.3$ & 0.92 & 22 & $A+V_{h}$ \\
\hline $3 \mathrm{bar} / 0.5 \mathrm{~min}$ & $70.0 \pm 0.8$ & $74.8 \pm 0.8$ & 9.6 & 3.5 & $104.9 \pm 0.2$ & $109.9 \pm 0.3$ & 1.0 & $\mathrm{Nd}$ & $\mathrm{V}_{\mathrm{h}}$-type \\
\hline 3bar/15min & $75.2 \pm 0.9$ & $80.3 \pm 0.8$ & 10.2 & 1.1 & $111.3 \pm 0.3$ & $116.7 \pm 0.5$ & 1.7 & $\mathrm{Nd}$ & $\mathrm{V}_{\mathrm{h}}$-type \\
\hline
\end{tabular}

${ }^{\mathrm{a}} \mathrm{T}_{\mathrm{o}}$ : onset temperature; $\mathrm{T}_{\mathrm{p}}$ : peak temperature; $\mathrm{R}$ : temperature range, calculated as $2\left(\mathrm{~T}_{\mathrm{p}}-\mathrm{T}_{\mathrm{o}}\right)$, $\Delta \mathrm{H}$ : enthalpy of gelatinization or melting of the complex

$\mathrm{Nd}$ : not determined 
Table 4. Size characteristics of starch granules for native and DIC treated standard maize starch before and after pasting in the Brabender;

\begin{tabular}{lllllll}
\hline Sample & \multicolumn{3}{c}{ Before pasting $^{2}$} & \multicolumn{3}{c}{ After pasting } \\
\hline DIC treatment $^{\mathrm{b}}$ & $\begin{array}{c}\mathrm{D}(\mathrm{v}, 0.5) \\
(\mu \mathrm{m})\end{array}$ & \multicolumn{1}{c}{$\left(\mathrm{D} / \mathrm{D}_{0}\right)^{3}$} & span & $\begin{array}{c}\mathrm{D}(\mathrm{v}, 0.5) \\
(\mu \mathrm{m})\end{array}$ & $\left(\mathrm{D} / \mathrm{D}_{0}\right)^{3}$ & span \\
\hline Native & 12.9 & 1 & 1.37 & 41.1 & 1 & 1.31 \\
1 bar/10min & 19.6 & 3.50 & 1.51 & 53.8 & 2.19 & 1.68 \\
$1 / 30$ & 19.3 & 3.35 & 1.62 & 40.0 & 0.92 & 1.31 \\
$1 / 60$ & 19.3 & 3.35 & 1.47 & 39.3 & 0.87 & 1.21 \\
$1 / 90$ & 19.4 & 3.40 & 1.54 & 36.0 & 0.67 & 1.05 \\
$1 / 120$ & 19.2 & 3.29 & 1.64 & 35.1 & 0.62 & 1.05 \\
$1 / 180$ & 21.7 & 4.76 & 1.91 & 36.6 & 0.71 & 1.07 \\
2 bar 2 min & 15.7 & 1.80 & 1.42 & 31.2 & 0.44 & 1.06 \\
$2 / 12$ & 19.4 & 3.40 & 1.67 & 32.4 & 0.49 & 1.35 \\
$2 / 30$ & 25.8 & 8 & 2.69 & 26.7 & 0.27 & 1.13 \\
$2 / 60$ & 27.7 & 9.90 & 2.43 & 23.8 & 0.19 & 1.3 \\
3 bar/ 0.5 min & 39.6 & 28.9 & 2.70 & 25.2 & 0.23 & 1.25 \\
$3 / 5$ & 61.0 & 105.7 & 2.45 & 29.6 & 0.37 & 1.76 \\
$3 / 10$ & 60.4 & 102.6 & 2.33 & 36.7 & 0.71 & 2.53 \\
\hline
\end{tabular}

$\mathrm{D}(\mathrm{v}, 0.5)$ : median diameter, $\left(\mathrm{D} / \mathrm{D}_{0}\right)^{3}$ : swelling ratio; span: $[(\mathrm{D}(\mathrm{v}, 0.9)-\mathrm{D}(\mathrm{v}, 0.1)] / \mathrm{D}(\mathrm{v}, 0.5)$

Values are means of triplicate determinations 